\title{
Emergency Resuscitation team roles: What constitutes a team and who's looking after the family?
}

\author{
J oanne E. Porter ${ }^{1}$, Simon J. Cooper ${ }^{2,3}$, Beverley Taylor ${ }^{2}$ \\ 1. School of Nursing and Midwifery, Monash University, Churchill, Victoria, Australia. 2. School of Nursing and Midwifery, \\ Monash University, Berwick, Victoria, Australia. 3. School of Nursing and Midwifery, University of Brighton (UK), Brighton, \\ United Kingdom.
}

Correspondence: Joanne E. Porter. Address: School of Nursing and Midwifery, Monash University, Churchill, Victoria, Australia. Email: joanne.porter@monash.edu

Received: August 17, 2013

DOI : $10.5430 /$ jnep.v4n3p124
Accepted: October 8, $2013 \quad$ Online Published: November 11, 2013

URL: http://dx.doi.org/10.5430/jnep.v4n3p124

\section{Abstract}

Aim of study: This study aimed to investigate the attitudes of personnel working in emergency departments on the constitution of a resuscitation team in particular the perceptions of the family liaison role.

Methods: A paper base survey on family presence during resuscitation was distributed to emergency personnel working in 18 public departments in the state of Victoria, Australia.

Results: A combination of nurses $(n=282)$ and doctors $(n=65)$ working in rural and metropolitan emergency departments, identified seven unique resuscitation team roles. Resuscitation teams were identified as comprising of three doctors, three nurses and one other which could be either. Respondents identified seven unique roles as consisting of a team leader, airway doctor, airway nurse, procedure doctor and procedure nurse, drugs nurse and a scribe. The respondents identified the following components as key to discussions with family members; emergency personnel, reassurance, diagnosis, regular updates, intervention, and prognosis (ER-DRIP).

Conclusion: The acronym ER-DRIP can be used as a reminder to emergency staff when speaking with family members during resuscitation events ensuring they receive all the necessary information and support.

\section{Key words}

Resuscitation, Teamwork, Family presence, Emergency department

\section{Introduction}

This paper forms part of a series of results papers, from a mixed methods study in-which Phase 1 incorporated a survey of emergency personnel in the State of Victoria, Australia. This paper presents results from this survey, regarding resuscitation team roles, with particular attention to the role of family support.

It has long been established that an effective resuscitation team must have clear and concise leadership which is associated with effective team cooperation and improved task performance ${ }^{[1]}$. Baker (2000) defined a team as two or more individuals with specialized knowledge and skills who perform specific roles and complete interdependent tasks to 
achieve a common goal or outcome ${ }^{[2]}$. The team leader should supervise patient care, make important clinical decisions and delegate work to other team members ${ }^{[3]}$. Additional members of the resuscitation team need clearly defined roles and responsibilities to ensure optimum patient safety and timely interventions ${ }^{[4]}$.

A clearly defined resuscitation team leader is essential with requirements for directive communication and clear clinical decision making as essential components to successful teamwork ${ }^{[5]}$. An observational study conducted by Miller (2012) which reviewed 39 trauma activations, measured teamwork and communication using the Clinical Teamwork Scale (CTS) to evaluate the effectiveness of the in-situ trauma simulation (ISTS) program ${ }^{[5]}$. The program showed significant improvements between baseline and simulation CTS scores with improved communication, role responsibility and role clarity ${ }^{[5]}$. In-situ training was also used in a similar study by Steinemann (2011) reviewing 100 resuscitations before training and 100 resuscitations after a teamwork training program ${ }^{[6]}$. Measurements of leadership, communication, decision making, situation awareness, cooperation and resource management, were made with significant improvements in performance ${ }^{[6]}$. The composition of the resuscitation team, roles and responsibilities were not defined in either of these studies however; both indicate that leadership and non-technical skills can be improved through training ${ }^{[5,7]}$.

The role of the team leader can be described as supervising patient care, making a major decisions and delegation of work to team members ${ }^{[3]}$. In typical metropolitan trauma centres the resuscitation team can comprise of between seven and fifteen members ${ }^{[3]}$. Typically, a team comprising of four nurses; medication, scribe and procedural nurses together with five doctors; anaesthesiologist, respiratory therapist, examination and team leader were listed ${ }^{[8]}$. Measurement of the workloads of four resuscitation members; the charge nurse, junior surgical resident, senior surgical resident, and emergency physician discovered that the junior resident had the highest mean total workload, which highlights the importance of the procedure doctor role ${ }^{[8]}$.

During resuscitation events team membership fluctuates in a dynamic environment making it difficult to anticipate available skills, and knowledge. It is therefore essential to clearly define roles and responsibilities ${ }^{[9]}$. Teamwork behaviours that promote Interprofessional collaboration, leadership, adaptability and team orientation are important ${ }^{[10,11]}$. Interprofessional resuscitation studies indicate that nursing and medical students have concerns over their professional identity and role all cation, however training does improve understanding of roles and perspectives ${ }^{[12]}$. Other studies have found that resuscitation training does define and clarify team roles during resuscitation, in particular, the role of team leader ${ }^{[13]}$.

Traditionally a registered nurses role during emergency resuscitations, the scribe requires effectiveness, expertise, confidence and assertiveness in order to accurately document the resuscitation event ${ }^{[14]}$. The nurse allocated to the scribe position should remain solely in that role, and is ideally an experienced senior emergency nurse ${ }^{[14]}$. Resuscitation training, which, although common, provides no mechanism to see that the taught skills are maintained ${ }^{[15]}$. Skills are usually taught in isolation with advanced life support (ALS) training ensuring emergency staff understand the algorithm's associated with resuscitation. However, not all the individual resuscitation team roles are practiced within the ALS curriculum. With the introduction of medical emergency teams (MET) response rates have improved ${ }^{[15]}$ however confusion remains regarding team roles and responsibilities as subsequent team members arrive, specifically where the first responder is a nurse ${ }^{[15]}$.

A designated family liaison role has been identified as being fundamental to the successful implementation and practice of family presence during resuscitation ${ }^{[16-18]}$. However, the role of family liaison remains undefined, and there appears to be no formal training and education programs. This paper aims to describe the findings of a Victorian survey of emergency personnel which lists the various resuscitation team roles and team configurations. It will discuss the essential elements of a meaningful interaction with family members and provide details of the suggested conversation points when acting in the role of family liaison. 


\section{Methods}

Following ethical approval a ten page paper based questionnaire on family presence during resuscitation, was distributed to 18 publically funded emergency departments in Victoria during the months of April - September 2012. The questionnaire was pilot tested with an Individual Content Validity Index of $\geq 0.90$ (expected I-CVI $\geq 0.78$ ) ${ }^{[19]}$. A designated staff member at each site distributed the survey to Emergency personnel and instructed them to return the survey in a self-addressed, pre-paid envelope. Results were then entered into the data software program SPSS V20 for analysis ${ }^{[20]}$. Descriptive frequencies and inferential statistics were conducted and open ended responses were analysed using an enumerative content analysis technique and thematic content analysis with conceptual mapping ${ }^{[21]}$.

\section{Results}

A total of 1382 surveys were distributed to both rural and metropolitan departments, 375 were returned, a response rate of $27 \%$. Twenty eight surveys were later excluded due to incomplete data, the total sample size is 347 . Sixty five doctors responded including interns $(n=4)$, residents $(n=12)$, physicians $(n=5)$ medical directors $(n=3)$ and emergency consultants $(n=31)$. Nursing staff $(n=282)$ included general nurses $(n=52)$, emergency certificated nurses $(n=172)$, unit managers ( $(n=5)$, associate nurse unit managers $(n=34)$ and nursing educators $(n=15)$. A total of $39 \%$ of participants $(n$ $=134)$ worked in a rural $\mathrm{ED}$, with $61 \%(\mathrm{n}=213)$ working in a metropolitan emergency department.

\subsection{Resuscitation team members}

When asked; "How many members in a resuscitation team?" 64\% $(\mathrm{n}=45)$ of Doctors and 69\% $(\mathrm{n}=180)$ of nurses stated it was between 4 and 6 members. Sixty four percent $(n=179)$ of nurses and $43 \%(n=28)$ of Doctors stated that they designate resuscitation team roles at the beginning of the shift. An open ended question was provided for participants to describe the resuscitation team members and their roles. An enumerative content analysis was conducted using frequency distribution figures to calculate the resuscitation team members ${ }^{[22]}$. There were some minor differences when describing what a resuscitation team, between nurses and doctors and also between rural and metropolitan emergency staff (see Table 1).

Table 1. Resuscitation Team Roles Frequency Distribution Scores of Open Ended Questions.

\begin{tabular}{|c|c|c|c|c|}
\hline Roles & $\begin{array}{l}\text { Rural doctors } \\
\mathbf{n}=16 \\
\mathbf{n}(\%)^{*}\end{array}$ & $\begin{array}{l}\text { Metro doctors } \\
\mathbf{n}=39 \\
\mathbf{n}(\%)^{*}\end{array}$ & $\begin{array}{l}\text { Rural nurses } \\
\mathbf{n}=92 \\
\text { n }(\%)^{*}\end{array}$ & $\begin{array}{l}\text { Metro nurses } \\
\mathbf{n}=98 \\
\mathbf{n}(\%)^{*}\end{array}$ \\
\hline Team leader & $13(81)$ & $33(85)$ & $53(58)$ & $53(54)$ \\
\hline Airway doctor & $13(81)$ & $29(74)$ & $57(62)$ & $77(79)$ \\
\hline Airway nurse & $10(63)$ & $27(69)$ & $65(71)$ & $93(95)$ \\
\hline Procedure doctor & $11(69)$ & $29(74)$ & $31(34)$ & $45(46)$ \\
\hline Procedure nurse & $9(56)$ & - & $44(48)$ & $52(53)$ \\
\hline Scribe & $10(63)$ & $30(77)$ & $77(84)$ & $92(94)$ \\
\hline Family liaison & $2(13)$ & $9(23)$ & $14(16)$ & $13(13)$ \\
\hline Drug nurse & - & $21(54)$ & $14(16)$ & $49(50)$ \\
\hline Scout & - & - & $29(32)$ & $25(26)$ \\
\hline Nursing supervisor & - & - & $18(20)$ & - \\
\hline
\end{tabular}

*Figures calculated using frequency distribution scores against the total number of respondents in each sub group.

Seven resuscitation team roles were identified as generic to: rural, metropolitan nurses and doctors including: team leader, airway doctor, airway nurse, procedure doctor, procedure nurse, scribe and a drug nurse. The mean number of team members ranged from 6-7 comprising of three doctors, three nurses and one other (either doctor or nurse). Interestingly, rural respondents reported a higher number of team members then metropolitan respondents (see Table 2). 
Table 2. Number of Resuscitation Team Members in Rural and Metropolitan Teams.

\begin{tabular}{lllll}
\hline Staff & Mean & Doctors & Nurses & Other \\
\hline Rural doctors & 7 & 3 & 3 & 1 \\
Metro doctors & 6 & 3 & 2 & 1 \\
Rural nurses & 7 & 3 & 3 & 1 \\
Metro nurses & 6 & 2 & 3 & 1 \\
\hline
\end{tabular}

Although it became clear that there are a number of roles that are interchangeable the respondents identified that certain resuscitation team members had specific responsibilities during the event. The team leader is responsible for the clinical decision making, remained "hands off" during the event and can be either a senior nurse or doctor depending upon the location of the emergency department. An emergency consultant was considered the ideal team leader by the majority of the respondent $(82 \%, \mathrm{n}=52)$ doctors, and $(73 \%, \mathrm{n}=206)$ nurses.

Respondents reported that the airway is managed by an airway doctor who intubates the patient together with the airway nurse who assists and ensures that the airway, breathing and ventilation are optimal. The procedure doctor and procedure nurse are responsible for all invasive procedures, including intravenous lines, intercostal catheters, cardiac monitoring and resuscitation equipment. The scribe ensures that the details of the resuscitation event are recorded, signed and correct. The drug nurse prepares and administers all resuscitation medication and infusions. Cardiac compressions, defibrillation and double checking of medications were highlighted as important roles however these tasks did not warrant assignment of a separate independent team member. In rural settings the resuscitation team includes the nursing supervisor whose role may include; team leader, drug nurse, and scout, patient transport, care of department and family liaison.

\subsection{Family liaison}

The family liaison role, although listed in the resuscitation team membership (see Table 2) did not rate highly overall with between $13 \%-23 \%$ of respondents noting its inclusion in the team. Further, $68 \%(n=44)$ of doctors and $81 \%(n=228)$ of nurses stated that they did not allocate the role prior to a resuscitation. Upon further questioning respondents were asked to indicate whose role it was to speak to family members.

A doctor and a nurse working together were considered the most appropriate combination to speak to the family during a resuscitation event. A doctor / nurse together liaising with family members was further confirmed as the preferred option when participants were asked to reflect between "Who does..." and "Who should speak to the family?" (see Table 3). A Chi-square test for independence (with Yates Continuity Correction) indicated no significant difference between doctors and nurses opinions of who does speak to the family $\mathrm{x}^{2}=5.9 p=.11$ and who should speak to the family $\mathrm{x}^{2}=4.0 p=.26^{[23]}$.

Table 3. Who does, and who should speak to the family?

\begin{tabular}{lllll}
\hline & \multicolumn{2}{l}{ Who does speak to family $\mathbf{n}(\%)$} & \multicolumn{2}{l}{ Who should speak to family n(\%) } \\
\cline { 2 - 5 } & Doctor* & Nurse* & Doctor* & Nurse* \\
\hline Doctor & $14(22)$ & $38(14)$ & $18(28)$ & $50(18)$ \\
Nurse & $15(23)$ & $50(18)$ & $8(12)$ & $48(17)$ \\
Doctor with nurse & $17(26)$ & $71(25)$ & $20(31)$ & $62(22)$ \\
Doctor, nurse with & $2(3)$ & $31(11)$ & - & $20(7)$ \\
nursing supervisor & & $27(10)$ & $4(6)$ & $24(9)$ \\
\hline Nursing supervisor & - & & & \\
\hline
\end{tabular}

*Total Nurses $(\mathrm{n}=282)$ Doctors $(\mathrm{n}=65)$

There was strong consensus between doctors and nurses with regard to who does and who should speak with the family. The doctors agreed that it was a doctor who was and should be speaking to the family (see Table $4 \mathrm{n}=11$ ) however 
suggested that a combination of both a nurse and doctor was preferred (see Table $4 \mathrm{n}=13$ ). Similarly the nurses indicated that it was more likely that a nurse was speaking to the family (see Table $5 \mathrm{n}=35$ ) however a doctor / nurse combination was the preferred option (see Table $5 \mathrm{n}=42$ ).

Table 4. Doctors - Comparing who does and who should speak to the family

\begin{tabular}{|c|c|c|c|c|c|}
\hline & Who sh & speak t & e family & & $T \pi$ \\
\hline & Doctor & Nurse & Nursing Supervisor & Doctor and Nurse & \\
\hline Doctor & 11 & 0 & 1 & 2 & 14 \\
\hline Who does Nurse & 3 & 8 & 0 & 1 & 15 \\
\hline speak to Nursing supervisor & 1 & 0 & 2 & 0 & 3 \\
\hline the familyDoctor and Nurse & 1 & 0 & 0 & 13 & 16 \\
\hline Doctor, nurse and Nursing supervisor & 0 & 0 & 0 & 2 & 2 \\
\hline Total & 18 & 8 & 4 & 20 & 64 \\
\hline
\end{tabular}

Table 5. Nurses - Comparing who does and who should speak to the family

\begin{tabular}{|c|c|c|c|c|c|c|c|}
\hline & & \multicolumn{5}{|c|}{ Who should speak to the family } & \multirow[b]{2}{*}{ Total } \\
\hline & & Doctor & Nurse & Nursing Supervisor & Doctor and Nurse & $\begin{array}{l}\text { Doctor, Nurse and } \\
\text { Nursing Supervisor }\end{array}$ & \\
\hline \multirow{5}{*}{$\begin{array}{l}\text { Who does } \\
\text { speak } \\
\text { to the family }\end{array}$} & Doctor & 26 & 0 & 2 & 6 & 1 & 37 \\
\hline & Nurse & 5 & 35 & 2 & 3 & 0 & 49 \\
\hline & Nursing supervisor & 3 & 1 & 14 & 2 & 1 & 26 \\
\hline & Doctor and Nurse & 3 & 7 & 2 & 42 & 5 & 70 \\
\hline & $\begin{array}{l}\text { Doctor, nurse and } \\
\text { Nursing supervisor }\end{array}$ & 2 & 1 & 3 & 5 & 9 & 31 \\
\hline Total & & 50 & 48 & 24 & 62 & 20 & 278 \\
\hline
\end{tabular}

A content analysis based on the open ended questions regarding what respondents deemed as essential information to give to relatives was formatted into conceptual maps to demonstrate the differences between doctors and nurses. Doctors in comparison to nurses were factual and direct with their information delivery. Five main categories emerged including patient diagnosis and prognosis. In comparison nurses expanded their descriptions of the main categories, including what happened and why it happened into the discussion (see Figure 1\&2). Further, nurses highlighted and importance of reassurance and regular updates for family and the need to consider the patient's wishes in the decision making process, answering relative's questions along the way.

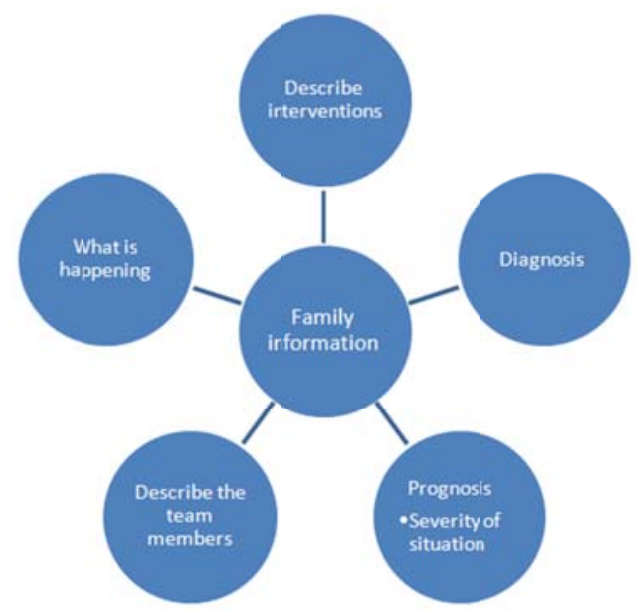

Figure 1. Conceptual map of family information: Doctors 


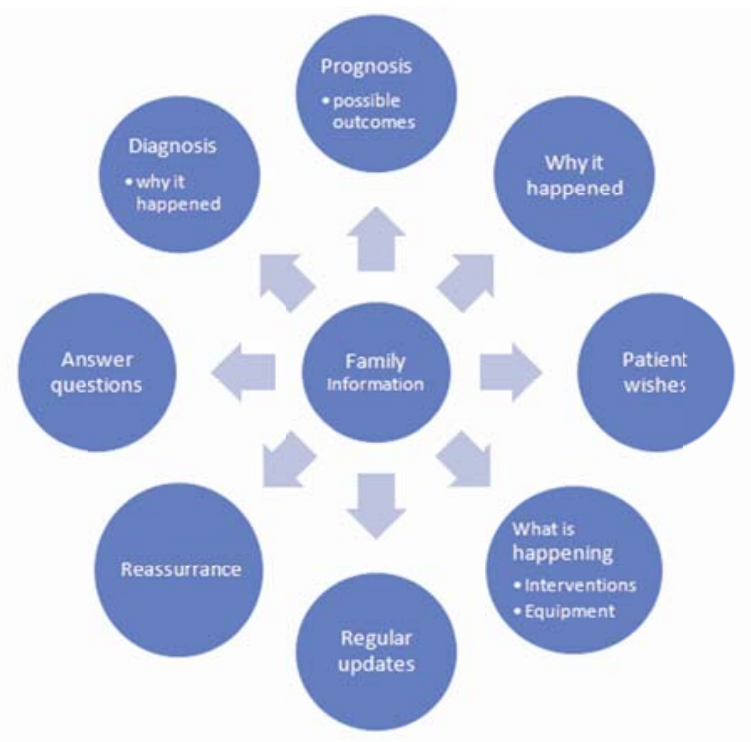

Figure 2. Conceptual map of family information: Nurses

\section{Discussion}

The findings from this State wide survey concurred with other studies on the constitution of roles of resuscitation team members and confirmed the diversity of configurations depending on location and presentation ${ }^{[3,8]}$. However, the literature tended to focus upon large trauma centres and/or metropolitan emergency departments with no studies highlighting the differences between rural settings with the utilisation of staff such as the nursing supervisor to fill a multitude of team roles. Although traditional training programs have targeted general emergency personnel, the nursing supervisor should be included in future team development programs.

Seven individual resuscitation team members were described; team leader, airway doctor / nurse, procedure doctor / nurse, scribe and drug nurse. This is similar to configurations found in the literature ${ }^{[24]}$. The family however, were left without an independent facilitator. Although a family support person, who remains independent from the resuscitation team, and can escort the family in to the resuscitation was highly recommended throughout the literature ${ }^{[25]}$.

A combination of a nurse and a doctor together were considered the ideal people to speak to the family. However it remains clear that emergency personnel lack the training and education to feel confident in dealing with all aspects of family care during a resuscitation. The acronym ER-DRIP has been developed from the survey findings which highlights the essential information that emergency personnel should disseminate to family members during a resuscitation (see Figure 3). Similar studies have attempted to develop guidelines for giving information to relatives however they tend to be generic and detailed ${ }^{[26]}$, ER-DRIP attempts to simplify the essential information unique for the emergency setting.

- $\quad \mathrm{E}-$ Emergency personnel (describe the members of the resuscitation team)

- $\mathrm{R}$ - Reassurance (everything possible is being done)

- $\quad \mathrm{D}$ - Diagnosis (what's wrong with the patient / cause of resuscitation if known)

- $\quad \mathrm{R}$ - Regular updates (describe the frequency of visits to give information)

- $\quad$ I - Interventions (describe the interventions being done to the patient)

- $\quad$ P - Prognosis / Presence (potential outcome / need to transport patient / severity of condition, suggest supported presence in resuscitation room)

Figure 3. ER-DRIP Information for families 
There is ongoing support for a designated family support person with many studies suggesting that it is essential for successful implementation of a family presence during resuscitation program ${ }^{[18,27-29]}$. However in practice, designating a family support person remains low on the priority list. Increasingly, the number of additional roles during a resuscitation event do not equate to an increase in the number of available emergency personnel, thus the family support role needs to be incorporated into the existing team roles especially in rural departments.

There is evidence to suggest that relatives felt that being present helped them through the grieving process ${ }^{[30]}$. Family members went on to say that they felt that being present also helped the patient through the resuscitation event ${ }^{[31]}$. It is also important that family members develop a clear understanding that everything that could be done, was, in attempt to save their relative ${ }^{[32]}$. Eventually assisting the family to come to terms with the patients prognosis and or possible death. Patients in one unique study reported that having a family member present encouraged them to fight harder to survive ${ }^{[33]}$. There remains evidence that supports the practice of having family present during resuscitation however emergency staff need to be provided with all the necessary skills in order for implementation into the emergency department. Adequate training, education and simulated practice will ensure that both nursing and medical staff feel they possess the necessary skills and techniques in order to ensure family are supported throughout the event while not comprising the resuscitation effort $^{[13,34]}$.

\section{Limitations of the study}

The questionnaire was distributed to only publically funded emergency departments, excluding departments that did not have both adults and paediatric presentations. Thus several large organisations were excluded from this study due to the inclusion criteria. Time constraints restricted inclusion of a number of departments due to lengthy ethical approval processes. Further research is recommended to explore family presence during resuscitation practice and implementation in emergency departments nationally and internationally.

\section{Conclusion}

Emergency personnel dealing with adult and paediatric presentations are required to fill a variety of roles and responsebilities including support of family members. Therefore, it is essential that education programs target the emergency personnel responsible for the patient and families well-being. Personnel need to equip themselves with the necessary tools in order to ensure that information is disseminated to family members in a clear and concise manner (for example the ER-DRIP). Further research is recommended to explore resuscitation team role delegation, especially in relation to liaising with family members.

\section{Funding}

This research received no specific grant from any funding agency in the public, commercial or not-for-profit sectors.

\section{Conflict of interest}

The authors declare that they have no conflict of interest

\section{Author contribution}

Author 1 was responsible for the study conception, literature review, questionnaire development, data collection, analysis and drafted manuscript. Author 2 and 3 provided expert guidance. Author 1 made final revisions to the paper and submitted.

\section{References}

[1] Hunziker, S., et al. Teamwork and leadership in cardiopulmonary resuscitation. Journal of the American College of Cardiology. 57(24): p. 2381-8. PMid:21658557 http://dx.doi.org/10.1016/j.jacc.2011.03.017 
[2] Baker, D.P., et al. Medical teamwork and patient safety: The Evidence-Based Relation. Literature Review. 2005 [cited 20135 th February]; Available from: http.//www.ahrq.gov/qual/medteam/.

[3] Sarcevic, A., et al. Leadership structures in emergency care settings: a study of two trauma centers. [Erratum appears in Int J Med Inform. 2011 Aug; 80(8): e48]. International Journal of Medical Informatics. 80(4): p. 227-38.

[4] Capella, J., et al. Teamwork training improves the clinical care of trauma patients. Journal of Surgical Education. 67(6): 439-43. PMid:21156305 http://dx.doi.org/10.1016/j.jsurg.2010.06.006

[5] Miller, D., et al. Improving Teamwork and Communication in Trauma Care Through In Situ Simulations. Academic Emergency Medicine. 2012; 19(5): 608-612. PMid:22594369 http://dx.doi.org/10.1111/j.1553-2712.2012.01354.x

[6] Steinemann, S., et al. In situ, multidisciplinary, simulation-based teamwork training improves early trauma care. Journal of Surgical Education. 68(6): p. 472-7. PMid:22000533 http://dx.doi.org/10.1016/j.jsurg.2011.05.009

[7] Steinemann, S., et al., Assessing teamwork in the trauma bay: introduction of a modified "NOTECHS" scale for trauma. American Journal of Surgery. 203(1): 69-75. PMid:22172484 http://dx.doi.org/10.1016/j.amjsurg.2011.08.004

[8] Parsons, S.E., et al., Assessment of workload during pediatric trauma resuscitation. The Journal of Trauma and Acute Care Surgery. 73(5): 1267-72.

[9] Wehbe-Janek, H., et al., Nurses' perceptions of simulation-based interprofessional training program for rapid response and code blue events. Journal of Nursing Care Quality. 27(1): 43-50. PMid:21849908 http://dx.doi.org/10.1097/NCQ.0b013e3182303c95

[10] Salas, E., D. Sims, and C. Burke, Is there a "big five" in teamwork? Small Group Research. 2005. 36 : $555-599$. http://dx.doi.org/10.1177/1046496405277134

[11] Beaubien, J. and D.P. Baker. The use of simulation for training teamwork skills in healthcare: how low can you go? Quality Safety in Healthcare. 2004; 13(1): 51-56. PMCid:PMC1765794 http://dx.doi.org/10.1136/qshc.2004.009845

[12] Bradley, P., S. Cooper, and F. Duncan, A mixed-methods study of interprofessionsl learning of resuscitation skills. Medical Education. 2009; 43: 912-922. PMid:19709016 http://dx.doi.org/10.1111/j.1365-2923.2009.03432.x

[13] Dagnone, J.D., et al. Interprofessional resuscitation rounds:a teamwork approach to ACLS education. Medical Teacher. 2008; 30: 49-54. PMid:18464132 http://dx.doi.org/10.1080/01421590701769548

[14] Molan, E. Scribe during emergency department resuscitation: Registered Nurse domain or up for grabs? Australasian Emergency Nursing Journal. 2013; 16: 45-51. PMid:23773535 http://dx.doi.org/10.1016/j.aenj.2013.03.001

[15] Hillman, K., et al., Redefining in-hospital resuscitation: the concept of the medical emergency team. Resuscitation. 2001; 48: 105-110. http://dx.doi.org/10.1016/S0300-9572(00)00334-8

[16] Agard, M., Creating advocates for family presence during resuscitation. Medsurg Nursing. 2008; 17(3): 155-60. PMid:18686419

[17] Booth, M.G., L. Woolrich, and J. Kinsella, Family witnessed resuscitation in UK emergency departments: a survey of practice. European Journal of Anaesthesiology, 2004. 21(9): 725-8. PMid:15595585

[18] Mian, P., Impact of a multifaceted intervention on nurses' and physicians' attitudes and behaviors toward family presence during resuscitation. Critical Care Nurse. 2007; 27(1): 52-61. PMid:17244859

[19] Polit, D.F. and C.T. Beck, The content validity index: are you sure you know what's being reported? Critique and recommendations. Research in Nursing \& Health. 2006; 29: 489-97. PMid:16977646 http://dx.doi.org/10.1002/nur.20147

[20] IBM Corp. Released 2011, IBM SPSS Statistics for windows, IBM Corp: Armonk, NY.

[21] Grbich, C., Qualitative Data Analysis. An Introduction. 2nd ed2013, London: Sage Publications. 336.

[22] Devore, J. and R. Peck, Statistics. The Exploration and Analysis of Data. 4th Ed ed2001, Australia: Duxbury, Thomson Learning.

[23] Preacher, K.J., Calculation for the chi-square test: An interactive calculation tool for chi-square tests of goodness of fit and independence [Computer software]. 2001: Available from: http://quantpsy.org.

[24] Henderson, S. and D. Ballesteros, Evaluation of a hospital-wide resuscitation team: does it increase survival for in-hospital cardiopulmonary arrest? Resuscitation. 2001; 48(2): 111-116. http://dx.doi.org/10.1016/S0300-9572(00)00263-X

[25] Marcy, C., et al., The relationship between the hospital setting and perception of family-witnessed resuscitation in the emergency department. . Resuscitation. 2006; 70(11): 74-79.

[26] Oman, K.S. and C.R. Duran, Health Care Providers' Evaluations of Family Presence During Resuscitation. JEN: Journal of Emergency Nursing. 2010; 36(6): 524-533. PMid:21078463 http://dx.doi.org/10.1016/j.jen.2010.06.014

[27] Holzhauser, K. and J. Finucane, Part B: a survey of staff attitudes immediately post-resuscitation to family presence during resuscitation. Australasian Emergency Nursing Journal. 2008; 11(3): 114-122. http://dx.doi.org/10.1016/j.aenj.2008.05.002

[28] Holzhauser, K. and J. Finucane, Staff attitudes to family presence during resuscitation: Part A: An interventional study. Australasian Emergency Nursing Journal. 2007; 10(3): 124-133. http://dx.doi.org/10.1016/j.aenj.2007.06.001

[29] Pasquale, M.A., et al., Family presence during trauma resuscitation: ready for primetime? Journal of Trauma. 2010; 69(5): 1092-1100. PMid:21068614 http://dx.doi.org/10.1097/TA.0b013e3181e84222 
[30] Mangurten, W., Effects of family presence during resuscitation and invasive procedures in a pediatric emergency department. Journal of Emergency Nursing. 2006; 32(3): 225-33. PMid:16730277 http://dx.doi.org/10.1016/j.jen.2006.02.012

[31] Knott, A. and C. Kee, Nurses' beliefs about family presence during resuscitation. Applied nursing research. 2005; $18(4)$ : $192-198$. PMid:16298694 http://dx.doi.org/10.1016/j.apnr.2005.07.002

[32] Kee, C.C., Nurses' beliefs about family presence during resuscitation. Applied nursing research. 2005; 18(4): 192-8. PMid:16298694 http://dx.doi.org/10.1016/j.apnr.2005.07.002

[33] Robinson, S.M., et al., Psychological effect of witnessed resuscitation on bereaved relatives. The Lancet. $1998 ; 352(9128): 614-7$. http://dx.doi.org/10.1016/S0140-6736(97)12179-1

[34] Madden, E., et al., Emergency nurses' current practices and understanding of family presence during CPR. Journal of Emergency Nursing. 2007; 33(5): 433-40. PMid:17884472 http://dx.doi.org/10.1016/j.jen.2007.06.024 